\title{
Investigation of thermal characteristics of CNF-based nanofluids for electronic cooling applications
}

\author{
S. Zainal Abidin ${ }^{1 *}$, I.S. Mohamad, ${ }^{1,2}$, A.Y. Bani Hashim ${ }^{3}$, N. Abdullah ${ }^{4}$, M.I.M. \\ Hafiz $^{1,2}$, N.A.B. Masripan ${ }^{1,2}$ and A. Abdullah ${ }^{1}$ \\ ${ }^{1}$ Faculty of Mechanical Engineering, Universiti Teknikal Malaysia Melaka, \\ Hang Tuah Jaya, 76100 Durian Tunggal, Melaka, Malaysia \\ *Email: syazwani2792@gmail.com \\ Phone: +60136663122; Fax: +6062346251 \\ ${ }^{2}$ Centre for Advanced Research on Energy, Universiti Teknikal Malaysia Melaka, \\ Hang Tuah Jaya, 76100 Durian Tunggal, Melaka, Malaysia \\ ${ }^{3}$ Faculty of Manufacturing Engineering, Universiti Teknikal Malaysia Melaka, \\ Hang Tuah Jaya, 76100 Durian Tunggal, Melaka, Malaysia \\ ${ }^{4}$ Centre for Foundation Studies, Universiti Pertahanan Nasional Malaysia, \\ Kem Sungai Besi, 57000 Kuala Lumpur, Malaysia
}

\begin{abstract}
A major problem being faced by existing coolants is the limited amount of heat that can be absorbed by the fluids. An innovative way to overcome this limitation is by utilizing a nano-coolant as a heat transfer medium in a cooling application. This paper was aimed at formulating an efficient nanofluid from Pyrograf III HHT24 carbon nanofibers (CNF) in a base fluid consisting of deionized water (DI) and ethylene glycol (EG) with polyvinylpyrrolidone (PVP) as the dispersant. The experiment was conducted by setting the variable weight percentage of CNF from $0.1 \mathrm{wt} \%$ to $1.0 \mathrm{wt} \%$, with the base fluid ratio of 90:10 (DI:EG) weight percent. Then, the thermal properties of the formulated nanofluids were investigated. The test on the thermal conductivity of the nanofluids showed that the highest thermal conductivity of $0.642 \mathrm{~W} / \mathrm{m} . \mathrm{K}$ in this experiment was produced when the concentration of nanofluid is $0.5 \mathrm{wt} \%$ at a temperature of $40^{\circ} \mathrm{C}$. Experimental investigations into the forced convective heat transfer performance of the CNF-based nanofluid in a laminar flow through a mini heat transfer test rig showed that the presence of nanoparticles enhanced the heat transfer coefficient as opposed to the original base fluid. The highest heat transfer coefficient was reported using nanofluid with a concentration of $0.6 \mathrm{wt} \%$ at $40^{\circ} \mathrm{C}$. The enhancement of the heat transfer coefficient was due to the higher thermal conductivity value. The Nusselt number was also calculated and presented in this paper. This study showed that the CNF-based nanofluids have a huge potential to replace existing coolants in electronic cooling applications. Thus, in order to commercialize nanofluids in practice, more fundamental studies are needed to understand the crucial parameters that affect their thermal characteristics.
\end{abstract}

Keywords: carbon nanofibers; nanofluid; thermal conductivity; heat transfer

\section{INTRODUCTION}

Carbon nanofiber (CNF) has amazing intrinsic mechanical properties that make it electrically and thermally conductive $[1,2]$. CNFs have a stacked-up structure due to the 
vapour deposition process employed in their production [3]. Carbon nanofibers are disjointed, highly graphitic and very well-suited for most polymer processing methods. They possess excellent mechanical properties, high electrical and thermal conductivity [4], which have made CNFs one of the choice materials for building cooling systems. The desired properties for a heat transfer fluid with particles are high thermal conductivity and extreme stability. Fluids having this combination of features are not in existence until the advent of nanofluids. Through the invention of nano-coolants, nanofluid technology contributes to a more energy-efficient and cost-effective process [5-9]. These nanofluids can be used in a wide range of industrial applications [10]. Heat transfer can be defined as the transfer of heat between a fluid and a surface due to the macroscopic motion of the fluid relative to the surface. Past researches revealed that nanofluids can enhance heat transfer [11-16]. Another study that was conducted also revealed that $\mathrm{Cu}$-ethylene glycol nanofluid exhibits an increased heat transfer capability [17-19]. Generally, the enhancement in the heat transfer coefficient is much higher than the increase in the effective thermal conductivity. The possible reasons associated to that fact are the increment in thermal conductivity, the shear-induced enhancement in the flow, and the high aspect ratio of the carbon nanotubes [20].

For the past two decades, promising results in experimental and theoretical studies in the literature reviews have shown that nanofluids have an extensive range of potential applications for heat transfer systems such as in automobile radiators [21], refrigerators $[6,22,23]$, solar collectors [24], mini channels [25] and electronics [26]. However, only a few studies of electronic coolants using nanofluids have been established as being related to CPU cooling [27]. Nguyen et al. [28] was the first person to conduct an experiment to study the effect of using nanofluids on the thermal performance of a water block system designed for CPU cooling. The study concluded that nanofluids enhance the heat transfer performance in the system, and this enhancement increases with an increase in the particle volume concentration. Roberts and Walker [29] also studied the thermal performance of a commercial liquid cooling system that used nanofluid as the coolant liquid. The study was conducted experimentally in a straight tube with $\mathrm{Al}_{2} \mathrm{O}_{3}$ /water nanofluid. The results were compared with a commercial water block. The results revealed that alumina-water nanofluid gives a better performance in liquid cooling systems. Recent studies by Nazari et al. [27] concluded that a cooling system that uses CNT nanofluids with added nanoparticles gives a better heat transfer performance compared to conventional fluids (ethylene glycol and water). The aforementioned studies were carried out on a CPU cooling system. Thus, the first aim of this present work was to develop and formulate an efficient nano-coolant produced from a mixture of carbon nanofibers, deionized water, ethylene glycol and dispersant. Then, the thermal properties of the nanofluid in terms of its thermal conductivity and heat transfer were studied. A mini heat transfer test rig was also designed in order to study the forced convective heat transfer in nanofluids under laminar flow conditions.

\section{METHODS AND MATERIALS}

\section{Materials}

The nanocarbon particles used in this study were Pyrograf III Carbon Nanofibers, High Heat Treated 24 (CNF HHT24) grade, which had been subjected to a high heat treatment with a temperature of up to $3000^{\circ} \mathrm{C}$. To facilitate the easy dispersion of nanoparticles in the nanofluids, polyvinylpyrrolidone (PVP) from Sigma-Aldrich Co. was chosen as a dispersant. The dispersant was added to lower the surface tension, increase the particle 
immersion and prevent fast sedimentation in the mixture. The properties of CNF HHT24 are shown in Table 1.

Table 1. Properties of Pyrograf III CNF HHT24.

\begin{tabular}{lc}
\hline Properties & Description \\
\hline Density & $2.0 \mathrm{~g} / \mathrm{cm}^{3}$ \\
Moisture & $<5 \mathrm{wt} \%$ \\
Fibre Diameter & $100 \mathrm{~nm}$ \\
Specific Surface Area & $41 \mathrm{~m}^{2} / \mathrm{g}$ \\
\hline
\end{tabular}

Deionized water (DI) with a density of $1.0 \mathrm{~g} / \mathrm{cm}^{3}$, which was used as the base fluid, was prepared in the laboratory using an ELGA LabWater purification system, while ethylene glycol, with a density of $1.1 \mathrm{~g} / \mathrm{cm}^{3}$, was purchased from Quality Reagent Chemical (QRëC).

\section{Synthesis of Nanofluids}

The preparation of the nanofluids in this study was carried out using a two-step method. The nanofluids that were formulated are shown in Figure 1. The nanofluids were synthesized with various mass fractions, where different masses of nanoparticles were added to $40 \mathrm{ml}$ of the base fluid composed of DI and EG, with the presence of polyvinylpyrrolidone (PVP). The experiment was conducted by setting the variable weight percentage of CNF from $0.1 \mathrm{wt} \%$ to $1.0 \mathrm{wt} \%$, with the base fluid ratio of 90:10 (DI:EG) weight percent. The suspension was homogenized for five minutes by using a Digital Homogenizer LHG-15 at a rotational speed of $10000 \mathrm{rpm}$. The homogenization was important to ensure that the solid particles inside the suspension were uniformly dispersed. Then, the nanofluid samples underwent an ultrasonication process at $25^{\circ} \mathrm{C}$ using an Elmasonic S3OH ultrasonicator for five minutes at a frequency of $37 \mathrm{kHz}$. The dispersion and stability of the nanofluids were then observed using a stability test rig (STR) to ensure that the nanofluids were in stable condition and well-homogenized.

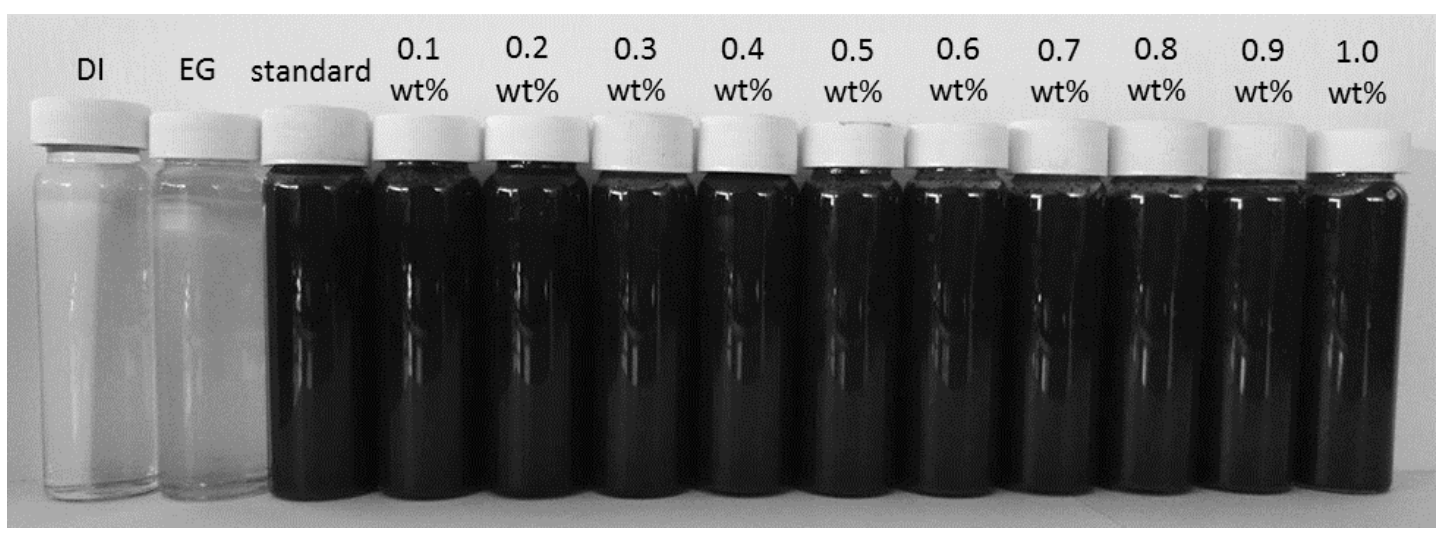

Figure 1. Nanofluid samples after undergoing homogenization and ultrasonication.

\section{Thermal Conductivity Measurement}

All the samples, which had been stabilised, were then tested for their thermal conductivity. The schematic diagram of the thermal conductivity test is shown in Figure 2. 


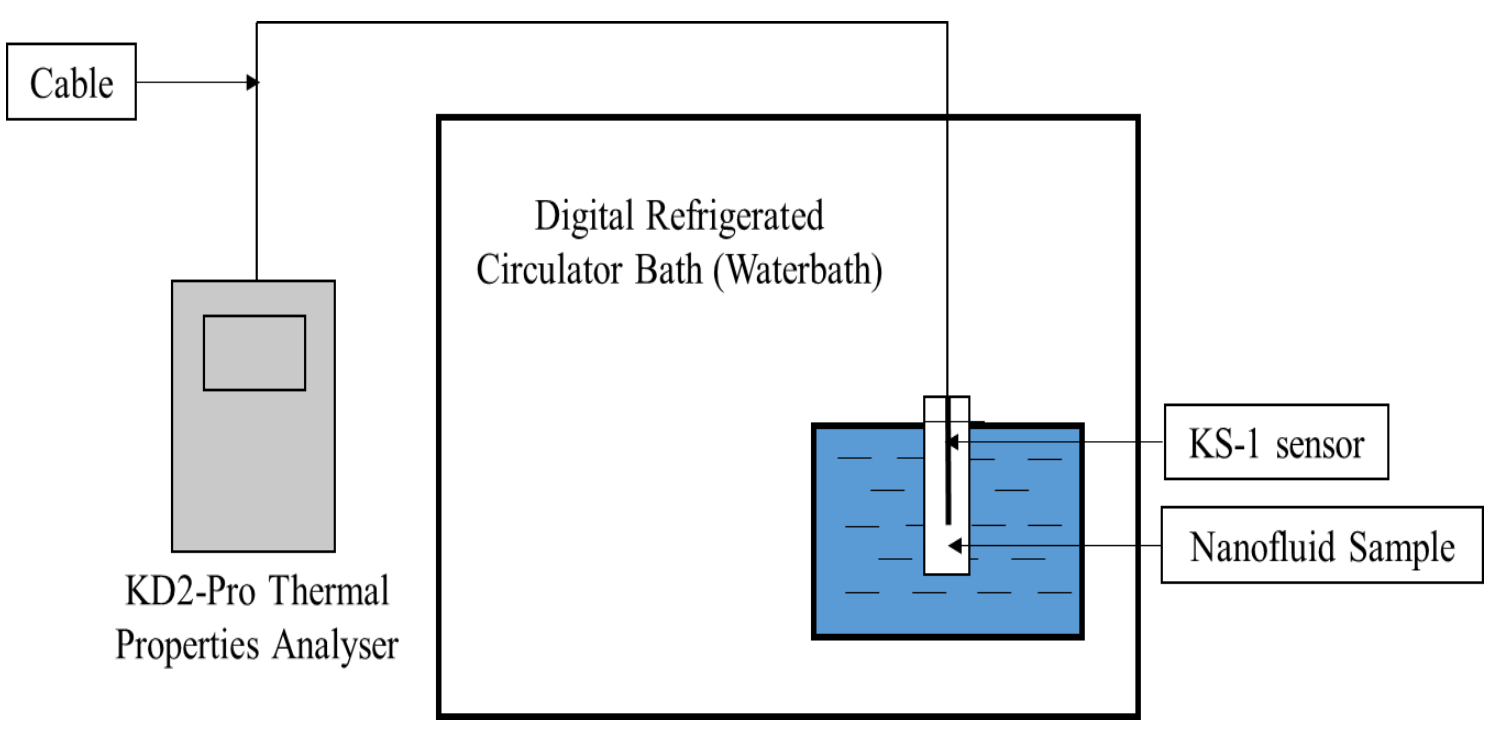

Figure 2. Schematic diagram for thermal conductivity testing.

A KD2-Pro Thermal Properties Analyser (Decagon Devices, Inc.) was used to measure the thermal conductivity of the nanofluids at three different temperatures of $6^{\circ} \mathrm{C}$, $25^{\circ} \mathrm{C}$ and $40^{\circ} \mathrm{C}$. This device met the standards of ASTM D5334 and IEEE 442-1981. A single-needle KS-1 sensor, with a length of $60 \mathrm{~mm}$ and a diameter of $1.3 \mathrm{~mm}$, was used to measure the thermal conductivity of the nanofluids. The KS-1 sensor provided a very small heat pulse, which was approximately less than $0.1 \mathrm{~W} / \mathrm{m} . \mathrm{k}$. In this experiment, to ensure accurate results, the testing was carried out three times for each nanofluid sample to obtain an average reading.

\section{Heat Transfer Experimental Setup}

A mini heat transfer test rig, as shown in Figure 3, was designed in order to study the thermal performance of the formulated nanofluids by utilising nanofluids as efficient coolants that can be used in liquid cooling systems. A model was built from the components that made up the central processing unit (CPU) of a liquid cooling system, which consisted of a copper coil (heating source), fan (cooling source), liquid pump, coolant tank and copper pipe. A direct current was used to run the cooling system. A copper coil with an outer diameter of $6.65 \mathrm{~mm}$, inner diameter of $4.35 \mathrm{~mm}$, thickness of $1.15 \mathrm{~mm}$, and heat exchange length of $81.40 \mathrm{~mm}$, was used as a heating source, which was drenched inside a refrigerated water bath. A liquid pump with a flow rate of $8 \mathrm{~L} / \mathrm{min}$ was used to circulate the nanofluids and base fluid during the test. A K-type thermocouple was used to measure the inlet and outlet temperatures of the nanofluids as they flowed through the copper coil. The thermocouples were attached to a data logger and the results were directly shown in the PicoLog data acquisition software. The readings were taken at water bath temperatures of $6^{\circ} \mathrm{C}, 25^{\circ} \mathrm{C}$ and $40^{\circ} \mathrm{C}$ following the constant flow of nanofluids. 


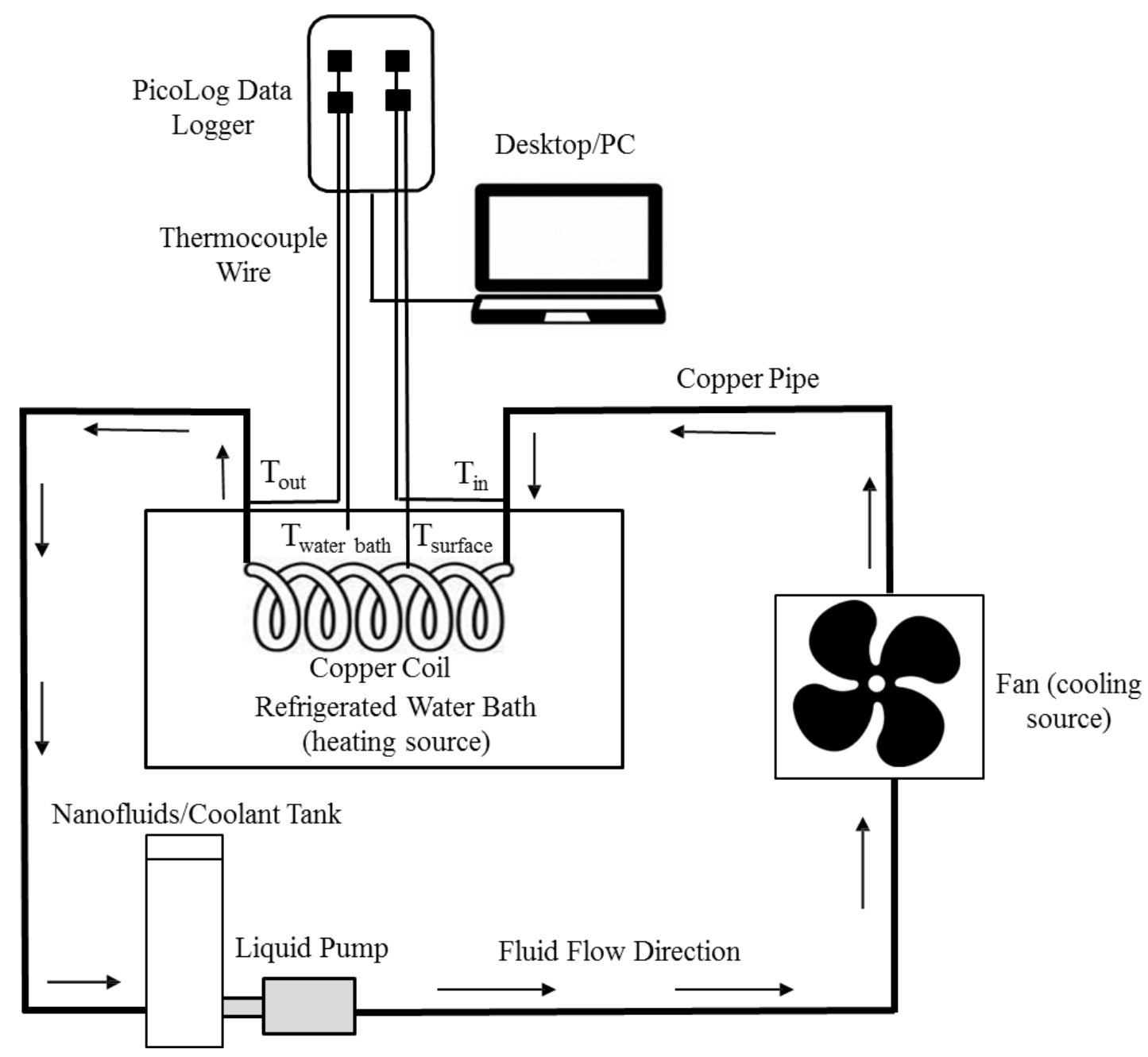

Figure 3. Schematic diagram of mini heat transfer test rig.

\section{RESULTS AND DISCUSSION}

\section{Thermal Conductivity}

In order to establish the reliability and accuracy of the measurements, the standard data obtained from the abovementioned experiment were compared to those established by the standards of the American Society of Heating, Refrigerating and Air Conditioning Engineers (ASHRAE). The comparison of the data is shown in Figure 4. It can be clearly seen from Figure 4 that the data for the base fluid are in good agreement with the data from ASHRAE. The thermal conductivity results were then represented graphically, as portrayed in Figure 5, to chart the effect of heat on each sample at various concentrations. A zero-weight percentage of CNF in a mixture of DI and EG (90:10) was used as a standard or datum to observe the enhancement of thermal conductivity at different temperatures. The results were also compared with the thermal conductivity of deionized water and ethylene glycol. Table 2 shows the thermal conductivity values of the standard data. 


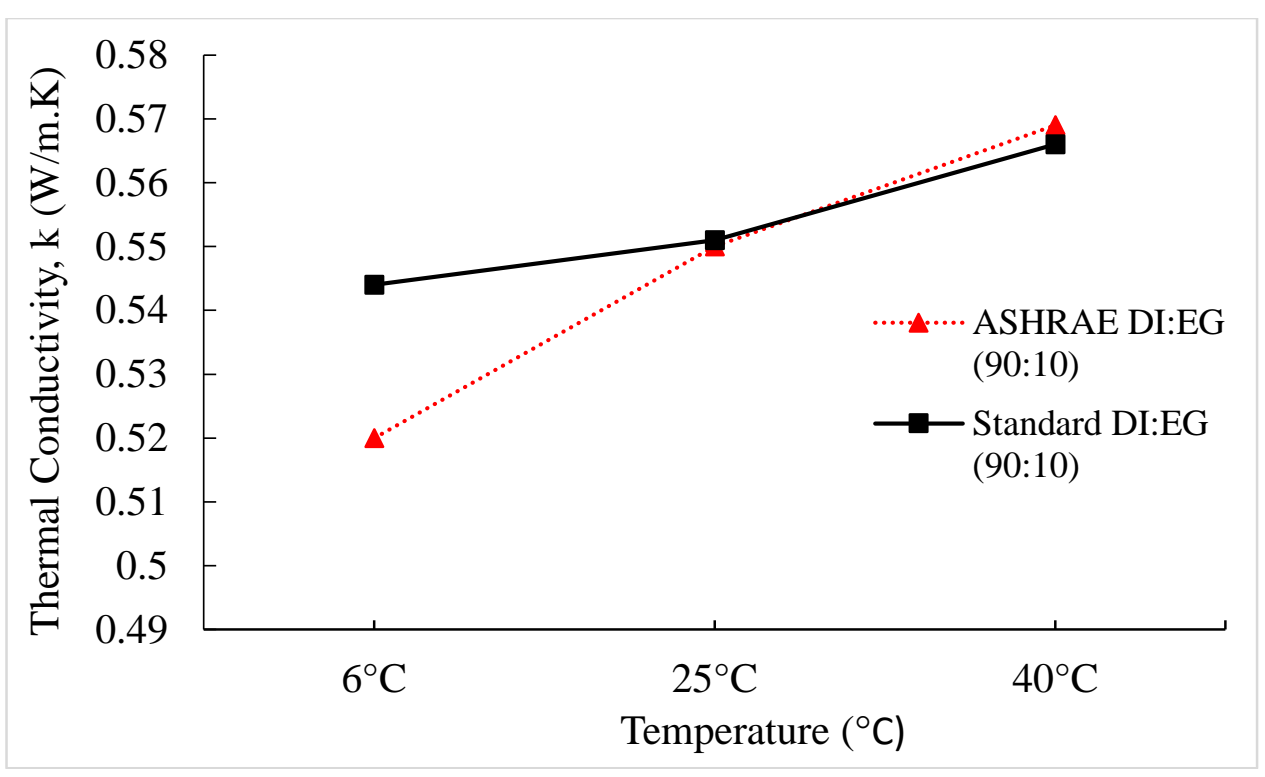

Figure 4. Thermal conductivity measurement validation compared to ASHRAE.

Table 2. Standard data for thermal conductivity.

\begin{tabular}{cccc}
\hline \multirow{2}{*}{ Sample } & \multicolumn{3}{c}{ Thermal Conductivity } \\
& $6^{\circ} \mathrm{C}$ & $25^{\circ} \mathrm{C}$ & $40^{\circ} \mathrm{C}$ \\
\hline Deionized Water (DI) & 0.546 & 0.570 & 0.595 \\
Standard DI:EG (90:10) & 0.544 & 0.551 & 0.566 \\
Ethylene Glycol (EG) & 0.219 & 0.223 & 0.235 \\
\hline
\end{tabular}

From the results obtained, most of the nanofluid samples exhibited an increasing thermal conductivity above that of the standard DI:EG (90:10) suspension and ethylene glycol. However, there was no significant enhancement when the results were compared to those of deionized water. The pure ethylene glycol had a lower thermal conductivity compared to deionized water. Thus, when these two fluids were mixed together, it led to a decrease in thermal conductivity. The results showed fluctuations for all the temperatures, but it could be seen that the increase in thermal conductivity varied with an increase in the percentage of nanoparticles. The highest thermal conductivity at all temperatures was recorded for $0.5 \mathrm{wt} \%, 0.6 \mathrm{wt} \%$ and $0.7 \mathrm{wt} \%$ samples. The highest thermal conductivity at $6^{\circ} \mathrm{C}$ was gained at $0.626 \mathrm{~W} / \mathrm{m} . \mathrm{K}$, whereas at $25^{\circ} \mathrm{C}$, the highest thermal conductivity reading was $0.635 \mathrm{~W} / \mathrm{m} . \mathrm{K}$, followed by $0.642 \mathrm{~W} / \mathrm{m} . \mathrm{K}$ at $40^{\circ} \mathrm{C}$. There were three samples with exceptionally low conductivities, in fact lower than the standard, which were the $0.8 \mathrm{wt} \%, 0.9 \mathrm{wt} \%$ and $1.0 \mathrm{wt} \%$ samples. The lowest thermal conductivities of $0.513 \mathrm{~W} / \mathrm{m} . \mathrm{K}$ and $0.524 \mathrm{~W} / \mathrm{m} . \mathrm{K}$ were observed in the $0.8 \mathrm{wt} \%$ sample at $6^{\circ} \mathrm{C}$ and $25^{\circ} \mathrm{C}$, respectively. Meanwhile, at $40^{\circ} \mathrm{C}$, the lowest thermal conductivity of $0.550 \mathrm{~W} / \mathrm{m} . \mathrm{K}$ was recorded by the $0.9 \mathrm{wt} \%$ sample. The increase in the nanoparticle ratio caused an increase in the viscosity of the base fluid and subsequently, caused a decline in the thermal conductivity of the nanofluids [30]. The viscosity of the base fluid affected the Brownian motion of the nanoparticles and the thermal conductivity of the nanofluids $[31,32]$. The decreasing trend in the thermal conductivity was also due to the increase in the size of the clusters and their regular parting from the base fluid [33]. The enhancement 
analysis was done to observe the trend, which was compared to the standard fluid (DI and EG). The enhancement percentages of the nanofluids are shown in Table 3.

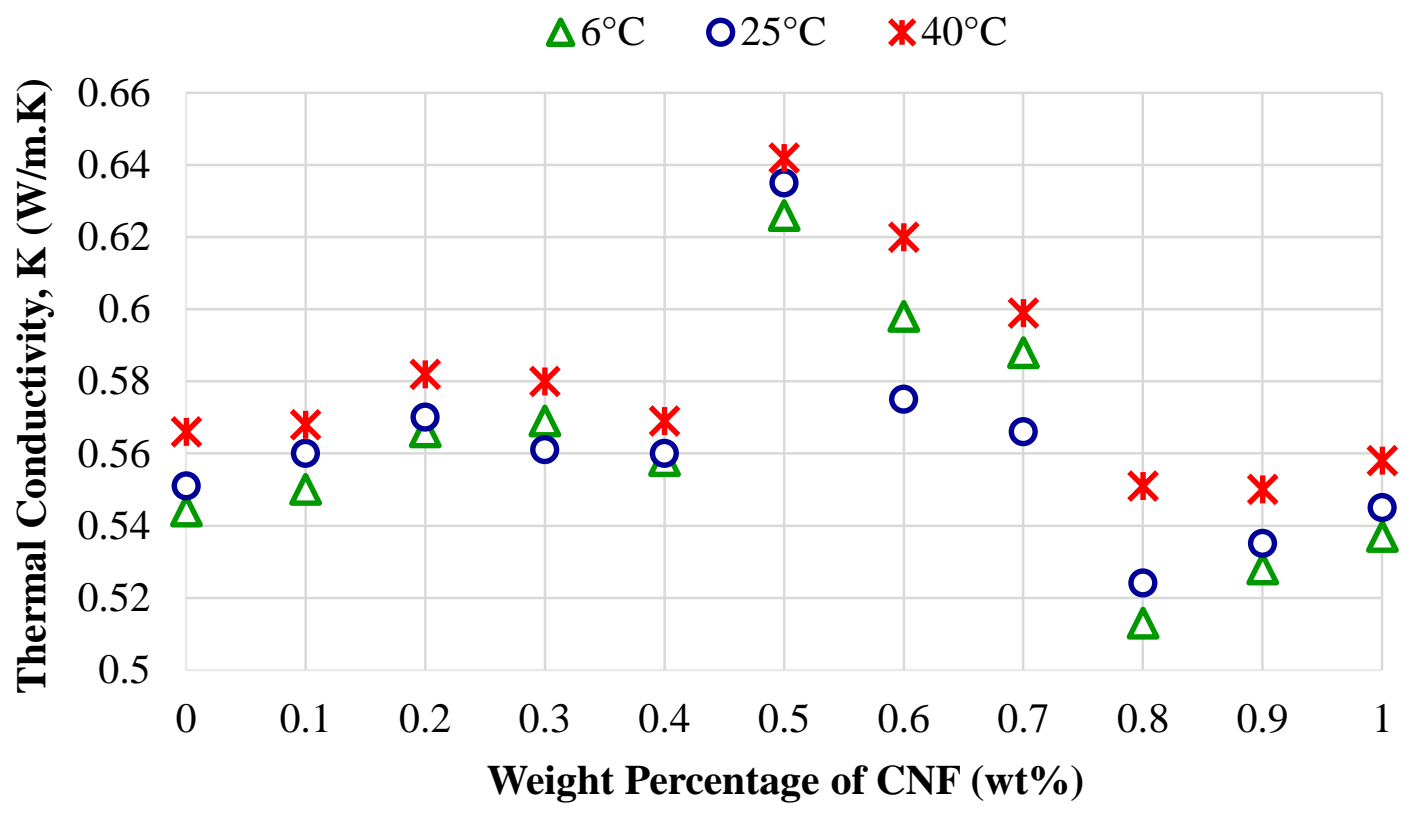

Figure 5. Thermal conductivity of CNF-based nanofluids at various concentrations when compared to standard DI:EG (90:10).

Table 3. Thermal conductivity enhancement percentages.

\begin{tabular}{c|ccc}
\hline \multirow{2}{*}{$\begin{array}{c}\text { CNF weight } \\
\text { percentage } \\
(\mathrm{wt} \%)\end{array}$} & \multicolumn{3}{|c}{ Percentage of Enhancement $(\%)$} \\
\cline { 2 - 4 } & $6^{\circ} \mathrm{C}$ & $25^{\circ} \mathrm{C}$ & $40^{\circ} \mathrm{C}$ \\
\hline 0.1 & 1.10 & 1.63 & 0.35 \\
0.2 & 4.04 & 3.45 & 0.36 \\
0.3 & 4.59 & 2.36 & 2.83 \\
0.4 & 2.57 & 1.64 & 0.53 \\
0.5 & 15.07 & 15.24 & 13.43 \\
0.6 & 9.93 & 4.36 & 9.54 \\
0.7 & 8.09 & 2.72 & 5.83 \\
0.8 & -5.69 & -4.90 & -2.65 \\
0.9 & -2.94 & -2.90 & -2.82 \\
1.0 & -3.71 & -3.53 & -1.41 \\
\hline
\end{tabular}

The highest percentage enhancements at $6^{\circ} \mathrm{C}, 25^{\circ} \mathrm{C}$ and $40^{\circ} \mathrm{C}$ were obtained by the $0.5 \mathrm{wt} \%, 0.6 \mathrm{wt} \%$ and $0.7 \mathrm{wt} \%$ nanofluids, respectively. The nanofluid sample with $0.5 \mathrm{wt} \%$ had the highest enhancement in thermal conductivity of $15.07 \%, 15.24 \%$ and $13.43 \%$ at $6^{\circ} \mathrm{C}, 25^{\circ} \mathrm{C}$ and $40^{\circ} \mathrm{C}$, respectively, while the percentage enhancement for 0.6 wt $\%$ was observed to be $9.93 \%, 4.36 \%$ and $9.54 \%$ at $6^{\circ} \mathrm{C}, 25^{\circ} \mathrm{C}$ and $40^{\circ} \mathrm{C}$, respectively. As for the $0.7 \mathrm{wt} \%$ sample, the enhancement in thermal conductivity was noted to be 8.09 $\%, 2.72 \%$ and $5.83 \%$ at $6^{\circ} \mathrm{C}, 25^{\circ} \mathrm{C}$ and $40^{\circ} \mathrm{C}$, respectively. The negative value indicated that there was no improvement in the thermal conductivity of CNF-based nanofluids, which means that the thermal conductivity was lower than the standard sample. It can be 
clearly seen from Table 3 that there was no enhancement for the $0.8 \mathrm{wt} \%, 0.9 \mathrm{wt} \%$ and $1.0 \mathrm{wt} \%$ samples. The lowest thermal conductivity enhancements of $-5.69 \%$ and $-4.90 \%$ were noted in the $0.8 \mathrm{wt} \%$ sample at $6^{\circ} \mathrm{C}$ and $25^{\circ} \mathrm{C}$, respectively. Meanwhile, at $40^{\circ} \mathrm{C}$, the $0.9 \mathrm{wt} \%$ sample had the lowest enhancement of $-2.92 \%$. Overall, it can be concluded that the $0.5 \%$ nanofluid sample gave the best enhancement to thermal conductivity of CNF-based nanofluids at all the tested temperatures. The weight percentage of CNT may give rise to abnormalities or irregular enhancements in the thermal conductivity, thus, explaining the irregular behaviour of the nanofluids [34-36]. Similar result was reported by the Hamilton-Crosser model [37], which showed that the thermal conductivity ratio increases nonlinearly with an increase in solid concentration. The results also showed that the rate of increase in the thermal conductivity at lower concentrations was much greater than that of at higher concentrations.

\section{Heat Transfer Coefficient}

A heat transfer test was conducted to ensure that the samples were able to serve their purpose of cooling and heating. Since fluid was used as the medium, the test was conducted through the forced convective heat transfer method. The flow of the fluid was assumed to be a laminar flow. The flow of fluid in a round tube or pipe is usually a laminar flow with the Reynolds number of less than 2300. The heat transfer rate between a moving fluid and a solid surface can be expressed by the following equation.

$$
Q=h A \Delta T_{1}
$$

where $Q$ is the forced convective heat transfer $(\mathrm{W}), h$ is the convective heat transfer coefficient of the system $\left(\mathrm{W} / \mathrm{m}^{2} . \mathrm{K}\right), A$ is the heat transfer area of the surface $\left(\mathrm{m}^{2}\right)$ and $\Delta T_{1}$ is the temperature difference between the surface and the bulk fluid $(\mathrm{K})$. On the other hand, the heat transfer rate can also be written as in Eq. (2).

$$
Q=m C_{p} \Delta T_{2}
$$

where $m$ is the mass of the water bath $(\mathrm{kg}), C_{p}$ is the specific heat of the water bath $(\mathrm{J} / \mathrm{kg} \cdot \mathrm{K})$ and $\Delta T_{2}$ is the temperature difference in the water bath $(\mathrm{K})$. Eq. (1) can be rearranged to obtain Eq. (3), as shown below.

$$
h=\frac{Q / A}{\Delta T_{1}}
$$

Eq. (2) was then inserted into Eq. (3) in order to obtain the experimental heat transfer coefficient, as shown in Eq. (4).

$$
h=\frac{m C_{p} \Delta T_{2}}{A\left(\Delta T_{1}\right)}
$$

In order to perform the calculation for the heat transfer coefficient of the fluid, relevant data were obtained and summarized as shown in Table 4 and Table 5. 
Table 4. Variables involved in the calculation of the heat transfer coefficient.

\begin{tabular}{cc}
\hline Variables Involved & Values \\
\hline Length of Copper Pipe, $L$ & $2.2 \mathrm{~m}$ \\
Outer Diameter of Copper Pipe, $O D$ & $0.013 \mathrm{~m}$ \\
Specific Heat of Water, $C_{p}$ & $4178 \mathrm{~J} / \mathrm{kg} . \mathrm{K}$ \\
Mass of Water Bath, $m$ & $3 \mathrm{~kg}$ \\
\hline
\end{tabular}

Table 5. Temperature difference for heat transfer coefficient calculation.

\begin{tabular}{l|ccc}
\hline \multicolumn{1}{c}{ Variable } & \multicolumn{3}{|c}{ Temperature difference at } \\
\cline { 2 - 4 } & $6^{\circ} \mathrm{C}$ & $25^{\circ} \mathrm{C}$ & $40^{\circ} \mathrm{C}$ \\
\hline$\Delta \mathrm{T}_{1}(\mathrm{DI})$ & 1.15 & 1.40 & 1.53 \\
$\Delta \mathrm{T}_{1}$ (standard) & 1.33 & 1.45 & 1.67 \\
$\Delta \mathrm{T}_{1}$ (EG) & 1.13 & 1.27 & 1.39 \\
$\Delta \mathrm{T}_{1}(0.5 \mathrm{wt} \%)$ & 1.69 & 1.60 & 1.72 \\
$\Delta \mathrm{T}_{1}(0.6 \mathrm{wt} \%)$ & 1.74 & 1.71 & 1.85 \\
$\Delta \mathrm{T}_{1}(0.7 \mathrm{wt} \%)$ & 1.68 & 2.04 & 2.01 \\
\hline$\Delta \mathrm{T}_{2}(\mathrm{DI})$ & 1.24 & 1.59 & 2.53 \\
$\Delta \mathrm{T}_{2}($ standard $)$ & 2.01 & 2.29 & 2.81 \\
$\Delta \mathrm{T}_{2}(\mathrm{EG})$ & 1.17 & 1.35 & 2.12 \\
$\Delta \mathrm{T}_{2}(0.5 \mathrm{wt} \%)$ & 2.60 & 2.58 & 3.10 \\
$\Delta \mathrm{T}_{2}(0.6 \mathrm{wt} \%)$ & 2.96 & 3.01 & 3.39 \\
$\Delta \mathrm{T}_{2}(0.7 \mathrm{wt} \%)$ & 2.77 & 3.23 & 3.34 \\
\hline
\end{tabular}

All the heat transfer coefficients were calculated based on the data from Table 4 and Table 5. Figure 6 shows the data of the heat transfer coefficient under different tested temperatures at $6^{\circ} \mathrm{C}, 25^{\circ} \mathrm{C}$ and $40^{\circ} \mathrm{C}$. It can be clearly seen that the convective heat transfer coefficient increased linearly with an increase in the tested temperature. The lowest heat transfer coefficient was recorded by the pure ethylene glycol without the addition of CNF nanoparticles, while the highest heat transfer coefficient was reported by the $0.6 \mathrm{wt} \%$ sample at $40^{\circ} \mathrm{C}$. The nanofluid concentration had a huge effect on the heat transfer coefficient, as when the concentration of the nanofluid increased, the convective heat transfer coefficient also increased. However, at a maximum concentration of 0.7 $\mathrm{wt} \%$, the convective heat transfer coefficient was relatively lower compared to those obtained by other concentrations. A strong reason for this was that the continuous operation of the liquid pump that ensured the flow of nanofluids in the test rig had caused depositions and clogging in the system. Numerous studies have been proposed to determine the reasons for the heat transfer enhancement. Xuan et al. [38] stated that the enhancement of the heat transfer of fluids is due to the high dispersion from the chaotic motion of nanoparticles that hastened the transport of energy within the fluid. Similar result was also reported by Luna et al. [39], who reported an increase in the heat transfer coefficient of the nanofluid, CuO-PVA, when compared with that of the original base fluid. 


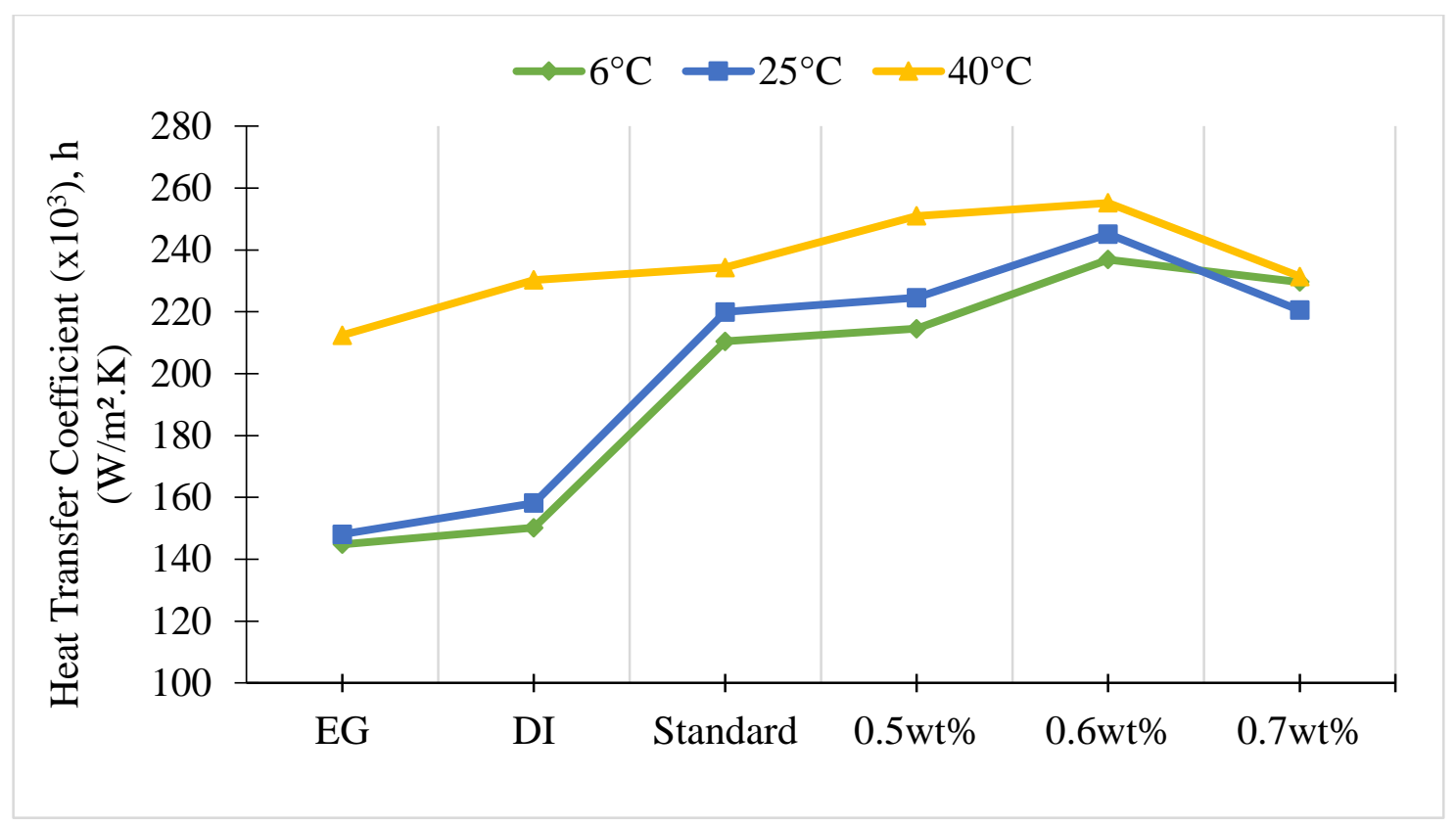

Figure 6. Heat transfer coefficient values at different temperatures.

Some researchers revealed that a large surface area promotes higher heat transfer between two media [40]. The reduction in particle size is represented by the effect of the nanoparticles on the surface area. As the size of the particles decreases, the surface area per unit volume increases. Thus, the heat transfer, which is directly related to the surface area increases, resulting in the improved efficiency of the nanoparticles in transferring heat to the base fluid [41]. A broader perspective was adopted by Duangthongsuk and Wongwises [42], who investigated the effect of thermo-physical properties on the prediction of the heat transfer coefficient, and concluded that the heat transfer coefficient of nanofluids is slightly greater than that of water. This statement was in agreement with most of the results obtained. Overall, the results of this study showed that the heat transfer properties of the nanofluids were higher than those of the standard solution. The heat transfer coefficient data were then used to obtain the experimental Nusselt number in order to determine the ratio of the convective to conductive heat transfer across the boundary. The Nusselt number was calculated from Eq. (5).

$$
N u=\frac{h D}{k}
$$

where $h$ is the experimental heat transfer coefficient, $D$ is the copper pipe diameter and $k$ is the experimental thermal conductivity of the fluid. The calculated experimental Nusselt numbers are shown in Table 6 . Table 6 shows the variation in the Nusselt numbers of the nanofluids, which is a function of the temperature as well as of the particle volume concentration. It was observed that the Nusselt numbers of the nanofluids were very much larger than those of deionized water. This was because the Nusselt number for water was 3.66, while the Nusselt number for the nanofluids started at a value of 4454.51 and increased with increasing concentration. However, the results showed fluctuation at 0.6 wt $\%$. The high Nusselt number was attributed to the large value of the heat transfer coefficient. A high Nusselt number indicated that the convection was controlling the 
thermal energy transported along the pipe surface. The pipe diameter, $D$, which was the required dimension in the case of a nanofluid in the laminar flow regime, was extremely small and contributed to the high heat transfer coefficient, hence leading to the increase in the Nusselt number. The heat transfer coefficient was subject to both the diameter of the pipe and the thermal conductivity of the fluid.

Table 6. Variation of Nusselt numbers at different temperatures.

\begin{tabular}{c|ccc}
\hline \multirow{2}{*}{ Sample } & \multicolumn{3}{|c}{ Nusselt Number } \\
\cline { 2 - 4 } & $6^{\circ} \mathrm{C}$ & $25^{\circ} \mathrm{C}$ & $40^{\circ} \mathrm{C}$ \\
\hline EG & 8597.63 & 8630.07 & 11750.11 \\
Standard & 502.96 & 5189.26 & 5382.22 \\
DI & 3575.35 & 3607.31 & 503.15 \\
$0.5 \mathrm{wt} \%$ & 4454.51 & 4597.43 & 5082.61 \\
$0.6 \mathrm{wt} \%$ & 515.02 & 5542.32 & 5350.88 \\
$0.7 \mathrm{wt} \%$ & 5076.72 & 5064.60 & 5022.42 \\
\hline
\end{tabular}

\section{CONCLUSIONS}

The addition of CNF nanoparticles to a mixture of DI and EG as the base fluid was proven to result in the enhancements of both thermal conductivity and heat transfer coefficients as compared to the standard samples. In the thermal conductivity test, the highest value recorded was $0.642 \mathrm{~W} / \mathrm{m} . \mathrm{K}$ for the nanofluid with a concentration of $0.5 \mathrm{wt} \%$ at a temperature of $40^{\circ} \mathrm{C}$. The experimental investigation into the forced convective heat transfer performance of the CNF-based nanofluid in a laminar flow through a mini heat transfer test rig showed that the presence of nanoparticles increased the heat transfer coefficient as opposed to the original base fluid. The highest heat transfer coefficient was reported by the $0.6 \mathrm{wt} \%$ sample at $40^{\circ} \mathrm{C}$. The enhancement in the heat transfer coefficient was due to the higher thermal conductivity values. The Nusselt numbers were also calculated and presented in this paper. Overall, this study showed that nanofluids have a great potential to be commercialized as conventional heat transfer fluids in electronic cooling applications. However, further studies are needed to determine the crucial parameters that affect the thermal characteristics of nanofluids such as the dispersion and stability of the nanofluids, sedimentation or clogging, and the nanoparticle size.

\section{ACKNOWLEDGEMENTS}

Authors would like to thank Universiti Teknikal Malaysia Melaka (UTeM), Universiti Pertahanan Nasional Malaysia (UPNM) and the Ministry of Higher Education (MOHE) for supporting this research under the grants FRGS/2010/FKM/SG03/1-F0076, FRGS/2/2013/ST05/UPNM/03/1, and FRGS/2/2013/SG02/FKP/02/2/F00176.

\section{REFERENCES}

[1] Chowdhury S, Olima M, Liu Y, Saha M, Bergman J, Robison T. Poly dimethylsiloxane/carbon nanofiber nanocomposites: fabrication and characterization of electrical and thermal properties. International Journal of Smart and Nano Materials. 2016;7:236-247. 
[2] Ravisankar B, Tara Chand V. Influence of nanoparticle volume fraction, particle size and temperature on thermal conductivity and viscosity of nanofluids- A review. International Journal of Automotive and Mechanical Engineering. 2013;8:1316-38.

[3] Lu W, Zu M, Byun JH, Kim BS, Chou TW. State of the art of carbon nanotube fibers: opportunities and challenges. Advanced Materials. 2012;24:1805-33.

[4] Feng L, Xie N, Zhong J. Carbon nanofibers and their composites: a review of synthesizing, properties and applications. Materials. 2014;7:3919-45.

[5] Jama M, Singh T, Gamaleldin SM, Koc M, Samara A, Isaifan RJ, et al. Critical Review on Nanofluids. Journal of Nanomaterials. 2016;2016:26.

[6] Redhwan AAM, Azmi WH, Sharif MZ, Hagos FY. Development of nanolubricant automotive air conditioning (AAC) test rig. MATEC Web of Conferences. 2017;90.

[7] Najiha M, Rahman M, Kadirgama K. Performance of water-based $\mathrm{TiO}_{2}$ nanofluid during the minimum quantity lubrication machining of aluminium alloy, AA6061T6. Journal of Cleaner Production. 2016;135: 1623-36.

[8] Zakaria I, Michael Z, Mohamed WANW, Mamat AMI, Azmi WH, Mamat R, et al. A review of nanofluid adoption in polymer electrolyte membrane (PEM) fuel cells as an alternative coolant. Journal of Mechanical Engineering and Sciences. 2015;8:1351-66.

[9] Hussein AM, Sharma KV, Bakar RA, Kadirgama K. Heat transfer enhancement with nanofluids - A Review. Journal of Mechanical Engineering and Sciences. 2013;4:452-61.

[10] Rao GS, KV S, Chary S, RA B, MM R, MM N. Experimental study on heat transfer coefficient and friction factor of $\mathrm{Al} 2 \mathrm{O} 3$ nanofluid in a packed bed column. Journal of Mechanical Engineering and Sciences. 2011;1:1-15.

[11] Khanafer K, Vafai K, Lightstone M. Buoyancy-driven heat transfer enhancement in a two-dimensional enclosure utilizing nanofluids. International Journal of Heat and Mass Transfer. 2003;46:3639-53.

[12] Yogeswaran M, Kadirgama K, Rahman MM, Devarajan R, Noor MM. Effect of $\mathrm{ZnO}$ nano materials on grinding surface finishing. International Journal of Automotive and Mechanical Engineering. 2015;12:2829-43.

[13] Usri NA, Azmi WH, Mamat R, Abdul Hamid K. Forced convection heat transfer using water- ethylene glycol (60:40) based nanofluids in automotive cooling system. International Journal of Automotive and Mechanical Engineering. 2015;11:2747-55.

[14] Nambeesan KPV, Parthiban R, Ram Kumar K, Athul UR, Vivek M, Thirumalini $S$. Experimental study of heat transfer enhancement in automobile radiator using A12O3/water-ethylene glycol nanofluid coolants. International Journal of Automotive and Mechanical Engineering. 2015;12:2857-65.

[15] Abdolbaqi MK, Azwadi CSN, Mamat R, Azmi WH, Najafi GN. Nanofluids heat transfer enhancement through straight channel under turbulent flow. International Journal of Automotive and Mechanical Engineering. 2015;11:2294-305.

[16] Hussein AM, Bakar RA, Kadirgama K, Sharma KV. Experimental measurements of nanofluids thermal properties. International Journal of Automotive and Mechanical Engineering. 2013;7:850-63.

[17] Eastman JA, Choi S, Li S, Yu W, Thompson L. Anomalously increased effective thermal conductivities of ethylene glycol-based nanofluids containing copper nanoparticles. Applied Physics Letters. 2001;78:718-20. 
[18] Abdul Hamid K, Azmi WH, Mamat R, Usri NA, Najafi G. Effect of temperature on heat transfer coefficient of titanium dioxide in ethylene glycol-based nanofluid. Journal of Mechanical Engineering and Sciences. 2015;8:1367-75.

[19] Abdullah HZ, Idris MI, Harun Z, Ismail AF, Yunos MZ, Hasan S. Influence of Polyethylene Glycol Additive on Performance of Polysulfone and Polyethersulfone Membrane. Journal of Mechanical Engineering and Sciences. 2014;6:746-52.

[20] Ding Y, Chen H, He Y, Lapkin A, Yeganeh M, Šiller L, et al. Forced convective heat transfer of nanofluids. Advanced Powder Technology. 2007;18:813-24.

[21] Mahbubul I, Saidur R, Amalina M. Thermal conductivity, viscosity and density of R141b refrigerant based nanofluid. Procedia Engineering. 2013;56:310-5.

[22] Chougule SS, Sahu SK. Comparative study of cooling performance of automobile radiator using Al2O3-water and carbon nanotube-water nanofluid. Journal of Nanotechnology in Engineering and Medicine. 2014;5:010901.

[23] Yusof TM, Arshad AM, Suziyana MD, Chui LG, Basrawi MF. Experimental study of a domestic refrigerator with $\mathrm{POE}-\mathrm{Al}_{2} \mathrm{O}_{3}$ nanolubricant. International Journal of Automotive and Mechanical Engineering. 2015;11:2243-52.

[24] Goudarzi K, Shojaeizadeh E, Nejati F. An experimental investigation on the simultaneous effect of $\mathrm{CuO}-\mathrm{H}_{2} \mathrm{O}$ nanofluid and receiver helical pipe on the thermal efficiency of a cylindrical solar collector. Applied Thermal Engineering. 2014;73:1236-43.

[25] Ho C, Chen W. An experimental study on thermal performance of $\mathrm{Al} 2 \mathrm{O}$ 3/water nanofluid in a minichannel heat sink. Applied Thermal Engineering. 2013;50:51622.

[26] Turgut A, Elbasan E. Nanofluids for electronics cooling. IEEE 20th International Symposium for Design and Technology in Electronic Packaging. 2014;35-7.

[27] Nazari M, Karami M, Ashouri M. Comparing the thermal performance of water, Ethylene Glycol, Alumina and CNT nanofluids in CPU cooling: Experimental study. Experimental Thermal and Fluid Science. 2014;57:371-7.

[28] Nguyen CT, Roy G, Gauthier C, Galanis N. Heat transfer enhancement using Al 2 O 3-water nanofluid for an electronic liquid cooling system. Applied Thermal Engineering. 2007;27:1501-6.

[29] Roberts NA, Walker D. Convective performance of nanofluids in commercial electronics cooling systems. Applied Thermal Engineering. 2010;30:2499-504.

[30] Tsai T-H, Kuo L-S, Chen P-H, Yang C-T. Effect of viscosity of base fluid on thermal conductivity of nanofluids. Applied Physics Letters. 2008;93:233121.

[31] Babu SR, Babu PR, Rambabu V. Effects of Some Parameters on Thermal conductivity of nanofluids and mechanisms of heat transfer improvement. International Journal of Engineering Research and Applications. 2013;3:2136-40.

[32] Idrus SS, Zaini N, Mohamad I, Abdullah N, Husin MM. Comparison of thermal conductivity for HHT-24-CNF-based nanofluid using deionized water and ethylene glycol. Jurnal Teknologi. 2015;77:85-9.

[33] Kole M, Dey T. Effect of prolonged ultrasonication on the thermal conductivity of $\mathrm{ZnO}-$ ethylene glycol nanofluids. Thermochimica Acta. 2012;535:58-65.

[34] Chol S. Enhancing thermal conductivity of fluids with nanoparticles. ASMEPublications-Fed. 1995;231:99-106.

[35] Mohamad IS, Chitrambalam ST, Hamid SBA, Chin W, Yau K, Febrian I. A comparison study on the heat transfer behavior of aqueous suspensions of rod 
shaped carbon nanotubes with commercial carbon nanotubes. Advanced Materials Research. 2013;667:35-42.

[36] Imran Syakir M, S Thiru C. Investigations on the thermo-physical properties of nanofluid-based carbon nanofibers under modified testing conditions. International Journal of Nanoelectronics and Materials. 2012;5:25-30.

[37] Esfe MH. Numerical investigation of effect of nanoparticles diameter on flow and heat transfer in lid-driven cavity with an inside hot obstacle filled with nanofluid. Journal of Current Research in Science. 2013;1:61.

[38] Xuan Y, Li Q, Hu W. Aggregation structure and thermal conductivity of nanofluids. AIChE Journal. 2003;49:1038-43.

[39] Luna IZ, Chowdhury AS, Gafur M, Khan RA. Measurement of Forced Convective Heat Transfer Coefficient of Low Volume Fraction CuO-PVA Nanofluids under Laminar Flow Condition. American Journal of Nanomaterials. 2016;3:64-7.

[40] Chopkar M, Das PK, Manna I. Synthesis and characterization of nanofluid for advanced heat transfer applications. Scripta Materialia. 2006;55:549-52.

[41] Hussein AM, Sharma K, Bakar R, Kadirgama K. A review of forced convection heat transfer enhancement and hydrodynamic characteristics of a nanofluid. Renewable and Sustainable Energy Reviews. 2014;29:734-43.

[42] Duangthongsuk W, Wongwises S. An experimental study on the heat transfer performance and pressure drop of $\mathrm{TiO} 2$-water nanofluids flowing under a turbulent flow regime. International Journal of Heat and Mass Transfer. 2010;53:334-44. 